\title{
Note
}

\section{Based on DNA sequences of ITS and $r p b 2$, Amylostereum orientale is reported for the first time in Japan}

\author{
Sandra Nogal-Prata ${ }^{a}$, Nitaro Maekawa $^{b}$, Toshinori Matozaki $^{b}$, \\ Margarita Dueñas ${ }^{a}$, María P. Martín ${ }^{a, ",}$ M. Teresa Telleria ${ }^{a}$ \\ a Departamento de Micología, Real Jardín Botánico, RJB-CSIC, Plaza de Murillo 2, 28014, Madrid, Spain \\ ${ }^{b}$ Fungus/Mushroom Resource and Research Center, Faculty of Agriculture, University of Tottori, 4-101 Koyama, \\ Tottori, 680-8553, Japan
}

\section{A R T I C L E I N F O}

Article history:

Received 18 August 2016

Received in revised form

13 December 2016

Accepted 25 December 2016

Available online 27 February 2017

Keywords:

Amylostereum laevigatum

Basidiomycota

China

Corticioid fungi

DNA barcoding

\begin{abstract}
A B S T R A C T
Amylostereum laevigatum has been reported from Japan growing on Cryptomeria japonica and Chamaecyparis obtusa. Using morphological and molecular data (internal transcribed spacer (ITS) nrDNA and rpb2 markers), we demonstrate that some specimens under A. laevigatum from Japan belong to A. orientale, a species described from China. Amylostereum orientale differs from A. laevigatum mainly in having smaller basidiospores. This is the first citation of A. orientale in Japan.
\end{abstract}

( 2017 The Mycological Society of Japan. Published by Elsevier B.V. All rights reserved.
Amylostereum Boidin (Russulales, Basidiomycota) is a genus of corticioid fungi mainly growing on conifers, with resupinate to reflexed basidiomes, and characterized by lamprocystidia and narrowly cylindrical to ellipsoid, smooth and amyloid basidiospores (Eriksson and Ryvarden 1973; Boidin and Lanquetin 1984; Telleria and Melo 1995). According to Mycobank (http://www.mycobank.org), five species are included in this genus: A. areolatum (Fr.) Boidin, A. chailletii (Pers.) Boidin (the type species), A. ferreum (Berk. \& M.A. Curtis) Boidin \& Lanq., A. laevigatum (Fr.) Boidin, and A. sacratum (G. Cunn.)
Burds. (三 Gloeopeniophorella sacrata (G. Cunn.) Hjorstam \& Ryvarden); and recently, He and Li (2013) described a new species from China, A. orientale S.H. He \& Hai J. Li. As mentioned in Slippers et al. (2003), for many years, A. areolatum and A. chailletii were known to establish obligate mutualistic relationships with woodwasps of the genus Sirex; Tabata and Abe (1997) showed that specimens of A. laevigatum from Japan establish this relationship with the woodwasps Urocerus antennatus Marlatt and U. japonicus Smith, effectively inoculating new wood (Slippers et al. 2003).

\footnotetext{
* Corresponding author. Fax: +34 914200157.

E-mail address: maripaz@rjb.csic.es (M.P. Martín).
} 
Amylostereum laevigatum has been reported in Japan (Tabata and Abe 1997) growing on Cryptomeria japonica D. Don and Chamaecyparis obtusa Sieb. \& Zucc. (Tabata et al. 2000). This species was originally described from Sweden (Fries 1828), where it is widespread (Eriksson and Ryvarden 1973; Legon 2005). It has been reported from Macaronesia: Madeira (Telleria et al. 2008), and the Azores islands (Dennis et al. 1977; Telleria et al. 2009a,b); as well as from North America (Ginns and Lefebvre 1993), and China (Maekawa et al. 2002).

Based on analysis of the internal transcribed spacer (ITS) region of nrDNA, the barcode for fungi (Schoch et al. 2012), as well as on the manganese-dependent peroxidase gene, Tabata et al. (2000) showed that specimens of A. laevigatum from Japan and A. laevigatum from France grouped separately; also, they reported differences in the spore size and in their hosts. Tabata et al. (2000), without providing spore dimensions, noted that specimens from Japan present smaller basidiospores than those from France. In the description of A. orientale, He and Li (2013) reported the spore size of this species as smaller than A. laevigatum from Europe, but they did not include specimens from Japan to confirm the presence of $A$. orientale in that country.

Therefore, the aim of this research was to clarify the identity of Amylostereum laevigatum from Japan using a barcoding approach (Schoch et al. 2012), and to provide an accurate revision of the morphological characters.

Specimens examined: JAPAN, Ochidani Park, Tottori City, Tottori Pref., on unidentified wood, 2 Jul 2008, leg. H. Suhara, TUMH61905 (TUMH); JAPAN, Nankan-machi, Tamana-gun, Kumamoto Pref., on Cryptomeria japonica, Jun 2004, leg. N. Maekawa, TUMH61916 (TUMH).

Cultures examined: JAPAN, Ochidani Park, 2 Jul 2008, leg. H. Suhara, TUFC11625 (isolated from TUMH61905; Tottori University); JAPAN, Nankan-machi, Jun 2004, leg. N. Maekawa, TUFC12106 (isolated from TUMH61916; Tottori University); JAPAN, without locality, cultures B1361 and B1362 isolated from Urocerus japonicus mycangium (Iowa State University); JAPAN, Motoyama, culture B1368 isolated from basidiospores obtained from basidiome growing on Cryptomeria japonica; JAPAN, B1369 from Chamaecyparis obtusa (Iowa State University). [Data from B1361, B1362, and B1369 as indicated in Tabata et al. (2000), and provided by T. Harrington. Data from B1368 as indicated in Tabata and Abe (1999)].

The genomic DNA from cultures B1361, B1362, B1368, B1369 was extracted using the FTA $^{\circledR}$ Indicating Micro Cards WB120211 (Whatman, Maidstone, England), following Telleria et al. (2014). The ITS nrDNA and rpb2 markers were amplified using Illustra ${ }^{\mathrm{TM}}$ PureTaq ${ }^{\mathrm{TM}}$ Ready-To-Go ${ }^{\mathrm{TM}}$ PCR Beads (GE Healthcare, Buckinghamshire, UK). The ITS nrDNA was amplified with the primer pair ITS1/ITS4 (White et al. 1990; Liu et al. 1999), following thermal cycling conditions described in Martín and Winka (2000). To amplify and sequence ribosomal polymerase two, subunit two (rpb2), regions 5-7, nested-PCR was performed with the following combination of primers: the primer pair RPB2-5F/RPB2-7.1R (Liu et al. 1999; Matheny et al. 2007) was used in the first amplification, and the pair RPB2-6F/RPB2-7.2R (Matheny et al. 2007) in the second one, using $1 \mu \mathrm{L}$ of the first amplification as target DNA. The PCR products were purified using the QIAquick Gel Extraction (Qiagen, Hilden, Germany) as indicated by the manufacturer.
All these protocols were carried out at the Real Jardin Botánico, RJB-CSIC (Madrid, Spain). Purified amplimers were sent to Macrogen (Belgium/South Korea) for sequencing.

From cultures TUFC12106 and TUFC11625, the genomic DNA was isolated following Hosaka and Castellano (2008). The ITS nrDNA and rpb2 markers were amplified using dNTPs, KOD FX Neo (TOYOBO Co., Ltd., Osaka, Japan) and PCR Buffer for KOD FX Neo. The ITS nrDNA was amplified using the primer pair ITS5/ITS4 (White et al. 1990), following a PCR program with an initial denaturation at $94{ }^{\circ} \mathrm{C}(1 \mathrm{~min})$ was followed by 35 cycles of $94{ }^{\circ} \mathrm{C}(15 \mathrm{~s}), 55^{\circ} \mathrm{C}(30 \mathrm{~s})$ and $72{ }^{\circ} \mathrm{C}$ ( $1 \mathrm{~min})$, and final extension at $72{ }^{\circ} \mathrm{C}(5 \mathrm{~min})$. The rpb2 was amplified as indicated above. The PCR products were purified using the MonoFas DNA Purification Kit (GL Sciences, Tokyo, Japan), and sequenced with ABI 3130 DNA sequencer (Applied Biosystems Inc., California, USA) in Tottori University.

Consensus sequences were assembled using Geneious Pro v9 (http://www.geneious.com; Kearse et al. 2012). Prior to the alignments, sequences generated in the present research were compared with homologous sequences in EMBL/GenBank/DDBJ (Cochrane et al. 2011) using the BLASTn algorithm (Altschul et al. 1997) to check for contamination. Two alignments, one to each marker, were generated including the new sequences and selected sequences from Amylostereum species from EMBL/GenBank/DDBJ. In both alignments, Echinodontium tinctorium (Ellis \& Everh.) Ellis \& Everh. sequences were included as outgroup, since in Tabata et al. (2000), the ITS sequence of this species, as well as other Echinodontium species closely matched the ITS sequence of Amylostereum.

Three analyses were performed for each alignment. First, a maximum parsimony (MP) analysis using the program PAUP 4.0a147 (Swofford 2003), as indicated in Telleria et al. (2013), with a default setting to stop the analyses at 100 trees. Exhaustive searches were conducted, and gaps treated as missing data. Tree scores, including tree length, consistency index (CI), homoplasy index (HI), and retention index (RI) were calculated from each exhaustive search; non-parametric searches (Felsenstein 1985) were used to calculate branch support (bootstrap, MPbs), performing 10,000 replicates using the fast-step option. Second, a maximum likelihood (ML) analysis was performed using the RAxML (Stamanakis 2014) in the CIPRES portal (CIPRES Science Gateway v.3.3; Miller et al. 2010), assuming a GTR model (default model); nonparametric bootstrap (MLbs) support (Felsenstein 1985) for each clade, based on 1000 replicates was tested. Finally, a Bayesian analysis (Larget and Simon 1999; Huelsenbeck et al. 2001) was performed using the software MrBayes v.3.2. (Ronquist et al. 2012), and assuming the general time reversible model (Rodríguez et al. 1990), including estimation of invariant sites and assuming a discrete gamma distribution with six categories $(\mathrm{GTR}+\mathrm{I}+\mathrm{G})$ selected by PAUP*4.0b10; the $50 \%$ majorityrule consensus tree and the posterior probability (pp) of the nodes were calculated from the remaining trees with MrBayes. Moreover, to assess whether a barcoding gap exists (Hebert et al. 2004), Kimura-2-parameter (K2P) pair-wise ITS distances were calculated using the software PAUP 4.0a147. On the basis of the widely used threshold for barcoding studies, a barcoding gap exists if the average interspecific difference is 10 times the average intraspecific difference (Hebert et al. 2004). 
The 12 new consensus sequences have been lodged in the EMBL/GenBank/DDBJ (Accession Numbers included in Figs. 1, 2). A matrix of 534 aligned nucleotide positions was produced for the ITS (459 characters are constant, 31 parsimony informative and 44 parsimony-uninformative). The 100 most parsimonious trees gave a length of 93 steps, CI $=0.8710$, $\mathrm{RI}=0.9481$, and $\mathrm{RC}=0.8257$. The topology of the parsimony strict consensus tree (not shown) was similar to the ML (not shown) and the $50 \%$ majority rule Bayesian tree (Fig. 1): sequences of A. laevigatum from Japan appeared separated from sequences of A. laevigatum from Europe. The sequences from Japan grouped in the A. orientale clade along with the A. orientale sequences from $\mathrm{He}$ and $\mathrm{Li}$ (2013) with very high support $(\mathrm{MPbs}=100 \%, \mathrm{MLbs}=98 \%, \mathrm{pp}=1.0)$. For the $r p b 2$ gene, an alignment with 702 characters (541 characters are constant, 113 parsimony-informative and 48 parsimony uninformative) was produced. The 100 most parsimonious trees gave a length of 246 steps, $\mathrm{CI}=0.7510, \mathrm{RI}=0.9402$, and $\mathrm{RC}=0.7061$. The rpb2 topologies obtained with each analysis were identical to each other; the $50 \%$ majority rule strict Bayesian tree is shown in Fig. 2. Sequences of A. laevigatum from Japan form a clade of their own, clearly separated from A. laevigatum from Europe. The alignments and trees were deposited in TreeBASE (Submission ID S20149).

On the other hand, the K2P distances matrix (Table 1) indicates that the maximum genetic distance between ITS sequences of any two isolates of A. laevigatum from Japan is 0.00196 , and between any two isolates of A. laevigatum from Europe is 0.00241; however, the large genetic distance between A. laevigatum from Japan and all the specimens of A. laevigatum from Europe (minimum 0.01894) confirms that they belong to different species. Moreover, the low value between A. laevigatum from Japan and A. orientale (maximum 0.00590), demonstrates that collections studied from Japan correspond to the species A. orientale. In Amylostereum, a barcoding gap exists in the ITS marker since the interspecific values are ten times higher than intraspecific values (Table 1), allowing identification to the species level.

The revision of morphological features of TUMH61905 and TUMH61916 was performed following Telleria and Melo (1995) and $\mathrm{He}$ and $\mathrm{Li}$ (2013). A short description of these collections is provided.

Basidiomes resupinate, adnate and coriaceus; hymenium and context brownish with numerous lamprocystidia; hyphal system monomitic, with generative hyphae with clamps, thin-walled; lamprocystidia thick-walled, brownish, 22-26 × 5-6 $\mu \mathrm{m}$; young cystidia subulate, hyaline, thinwalled, smooth; basidia subclavate to clavate, with a basal clamp connection and four sterigmata, $26 \times 5-6 \mu \mathrm{m}$; basidiospores ellipsoid, hyaline, thin-walled, amyloid, $6.5 \times 3.5-4.5 \mu \mathrm{m}$ (very few observed).

As detected in Tabata et al. (2000), our molecular and morphological analyses clearly separate Japanese A. laevigatum from European A. laevigatum. The position in the ITS nrDNA tree, as well as the genetic K2P distance values obtained show that Japanese collections studied belong to A. orientale, instead of A. laevigatum. Although no rpb2 sequences from $A$. orientale from China are included in our analyses, the position of the Japanese collections in the rpb2 tree, forming a group of its own separated from A. laevigatum, support our

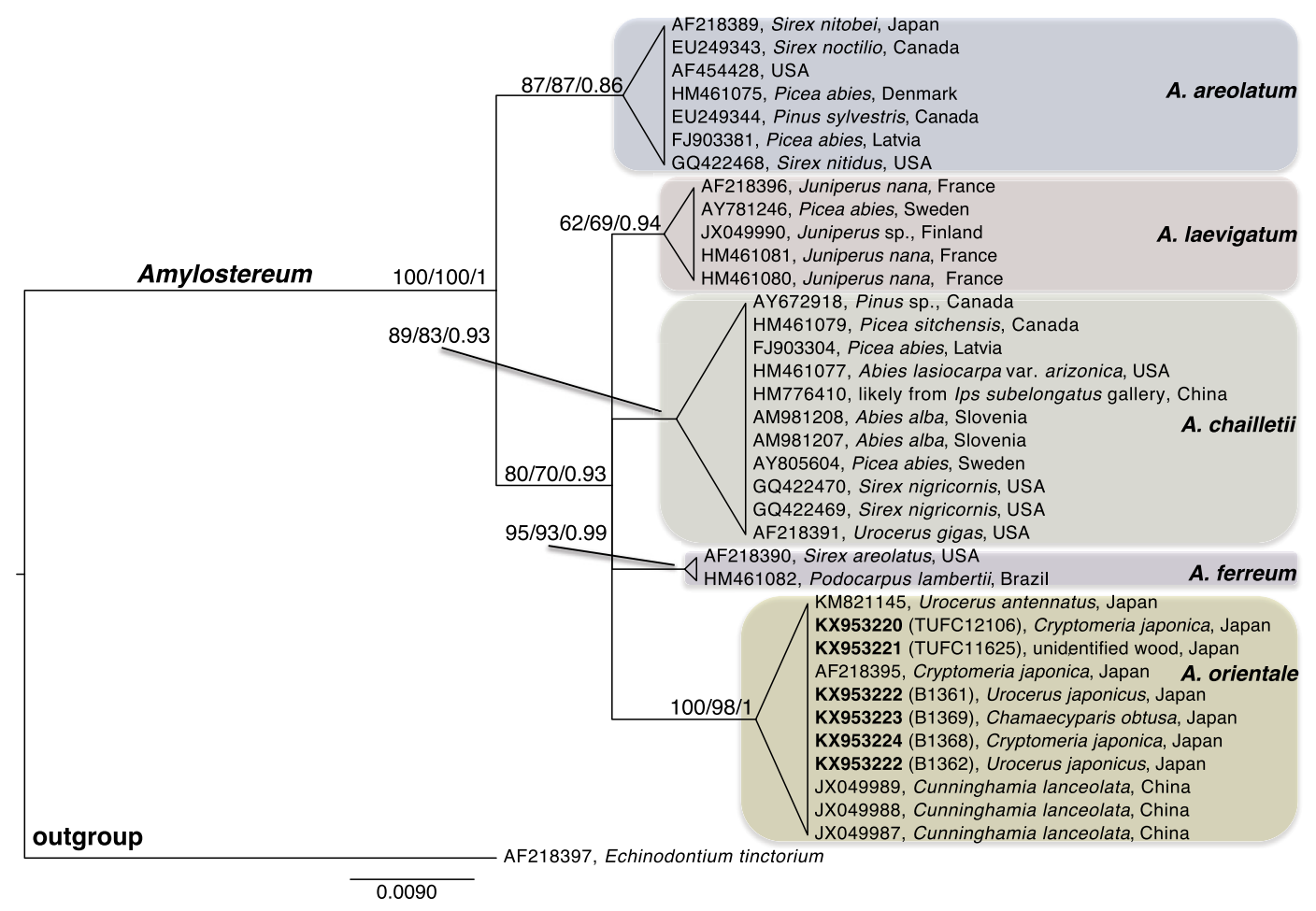

Fig. 1 - Phylogenetic tree obtained from Bayesian inference of ITS sequences of Amylostereum spp., including Echinodontium tinctorium as outgroup. The host trees and localities are shown next to the accession numbers. Parsimony bootstrap support (MPbs), likelihood bootstrap support (MLbs) and posterior probability (pp) indicated above branches. New sequences obtained in this work are marked in bold face, and culture numbers are provided. 


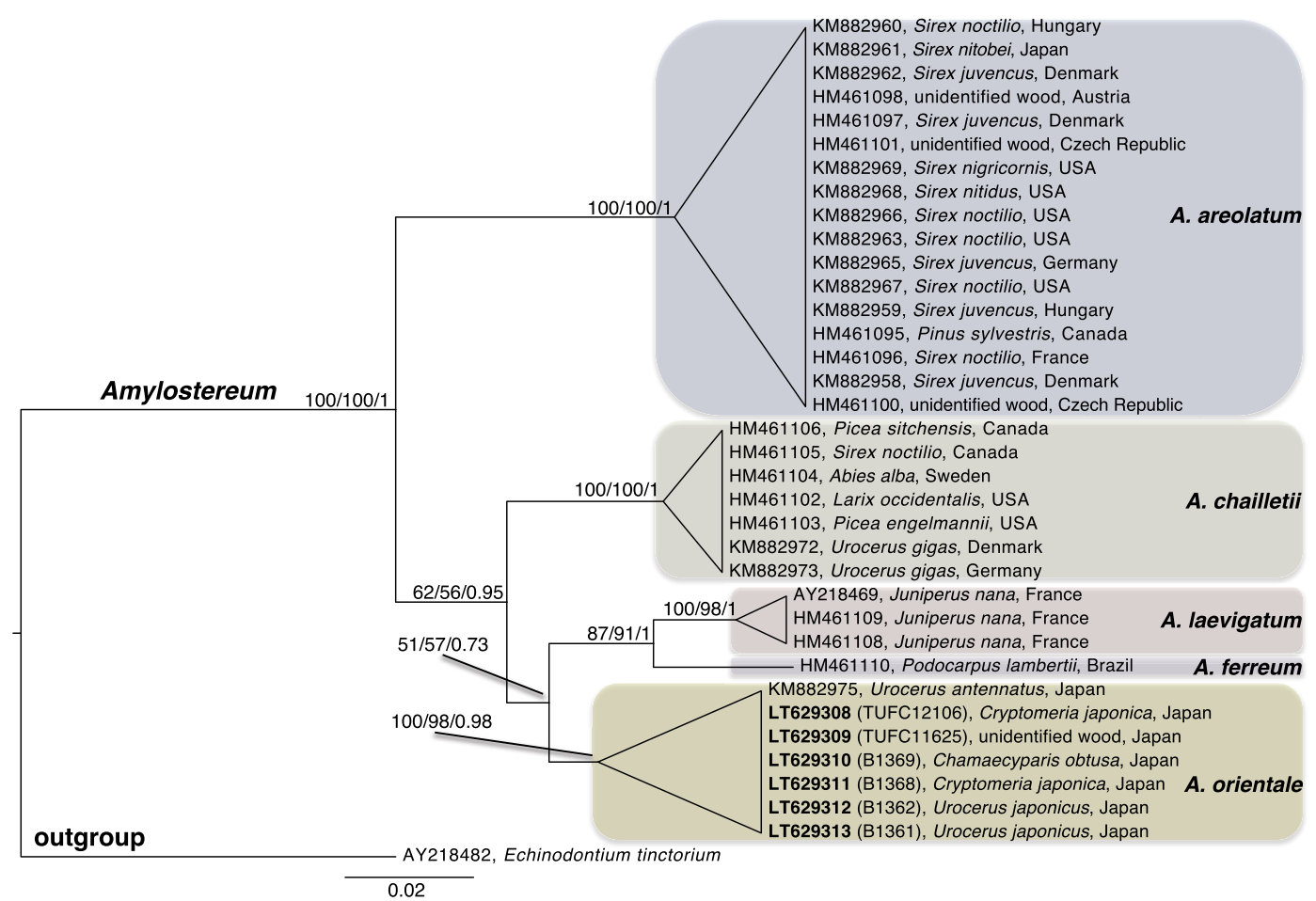

Fig. 2 - Phylogenetic tree obtained from Bayesian inference of rpb2 sequences of Amylostereum spp. including Echinodontium tinctorium as outgroup. The host trees and localities are shown next to the accession numbers. Parsimony bootstrap support (MPbs), likelihood bootstrap support (MLbs) and posterior probability (pp) indicated above branches. New sequences obtained in this work are marked in bold face, and culture numbers are provided.

Table 1 - Matrix of pairwise intra- and interspecific Kimura-2 Parameter (K2P) distance among Amylostereum spp. ITS nrDNA sequences. The gray shading indicates the interspecific K2P among A. orientale and A. laevigatum, from Japan and Europe.$$
2
$$
3 4 5

1 Amylostereum orientale

2 Amylostereum laevigatum, Japan

3 Amylostereum laevigatum, Europe 0

4 Amylostereum chailletii

5 Amylostereum ferreum

6 Amylostereum areolatum

$\begin{array}{ll}0 & \\ 0.00590 & 0.00196 \\ 0.01881 & 0.01894 \\ 0.02189 & 0.01990 \\ 0.02556 & 0.02360 \\ 0.03338 & 0.03530\end{array}$

0.00241

0.00991

0.01173

0.02547

\subsection{2 \\ 0.01381}

0.03124
0.02738 0.00590

conclusion. These are the first confirmed records of A. orientale in Japan.

\section{Acknowledgments}

We are grateful to Thomas Harrington of Iowa State University (USA) for loan of cultures B1361, B1362, B1368 and B1369; to Marian Glenn for her kind English revision. The research was supported by Plan Nacional I+D+i CGL2012-35559 and CGL2015-67459-P projects.

\section{R E F E R E N C E S}

Altschul SF, Madden TL, Schäffer AA, Zhang J, Zhang Z, Miller W, Lipman DJ, 1997. Gapped BLAST and PSI-BLAST: a new generation of protein database search programs. Nucleic Acids
Research 25: 3389-3402; http://dx.doi.org/10.1093/nar/ 25.17.3389.

Boidin J, Lanquetin P, 1984. Le genre Amylostereum (Basidiomycètes) intercompatibilités partielles entre espèces allopatriques. Bulletin de la Société Mycologique de France 100: 211-236.

Cochrane G, Karsch-Mizrachi I, Nakamura Y, 2011. The international nucleotide sequence database collaboration. Nucleic Acids Research 39: D15-D18; http://dx.doi.org/10.1093/ nar/gkr1006.

Dennis RWG, Reid DA, Spooner B, 1977. The fungi of the Azores. Kew Bulletin 31: 85-136; http://dx.doi.org/10.2307/4117263.

Eriksson J, Ryvarden L, 1973. The Corticiaceae of North Europe Volume 2, Aleurodiscus-Confertobasidium. Fungiflora, Oslo; http:// dx.doi.org/10.2507/4117263.

Felsenstein J, 1985. Confidence limits on phylogenies: an approach using the bootstrap. Evolution 39: 783-791; http:// dx.doi.org/10.2307/2408678.

Fries EM, 1828. Elenchus Fungorum: sistens commentarium in Systema Mycologicum, vol 1. Ernestus Mauritius, Greifswald. 
Ginns J, Lefebvre MNL, 1993. Lignicolous corticioid fungi (Basidiomycota) of North America: systematics, distribution, and ecology. American Phytopathological Society, Mycologia Memoir 19: 1-227.

He SH, Li HJ, 2013. Amylostereum orientale sp. nov. (Basidiomycota, Russulales) and first report of A. areolatum in China based on morphological and molecular characters. Nordic Journal of Botany 31: 728-733; http://dx.doi.org/10.1111/j.17561051.2013.01756.x.

Hebert PD, Stoeckle MY, Zemlak TS, Francis CM, 2004. Identification of birds through DNA barcodes. PLoS Biology 2: e312; http://dx.doi.org/10.1371/journal.pbio.0020312.

Hosaka K, Castellano MA, 2008. Molecular phylogenetics of Geastrales with special emphasis on the position of Sclerogaster. Bulletin of the National Museum of Nature and Science. Series B, Botany 34: 161-173.

Huelsenbeck JP, Ronquist F, Nielsen R, Bollback JP, 2001. Bayesian inference of phylogeny and its impact on evolutionary biology. Science 294: 2310-2314; http://dx.doi.org/10.1126/ science.1065889.

Kearse M, Moir R, Wilson A, Stones-Havas S, Cheung M, Sturrock S, Buxton S, Cooper A, Markowitz S, Duran C, Thierer T, Ashton B, Mentjies P, Drummond A, 2012. Geneious Basic: an integrated and extendable desktop software platform for the organization and analysis of sequence data. Bioinformatics 28: 1647-1649; http://dx.doi.org/10.1093/ bioinfromatics/bts199.

Larget B, Simon DL, 1999. Markov chain Monte Carlo algorithms for the Bayesian analysis of phylogenetic trees. Molecular Biology and Evolution 16: 750-759.

Legon NW, 2005. Profiles of fungi 138. Amylostereum laevigatum. Mycologist 13: 128.

Liu YJ, Whelen S, Hall BD, 1999. Phylogenetic relationships among ascomycetes: evidence from an RNA polymerse II subunit. Molecular Biology and Evolution 16: 1799-1808. http://mbe. oxfordjournals.org/content/16/12/1799.long.

Maekawa N, Yang ZL, Zang M, 2002. Corticioid fungi (Basidiomycetes) collected in Sichuan Province, China. Mycotaxon 83: 81-95.

Martín MP, Winka K, 2000. Alternative methods of extracting and amplifying DNA from lichens. The Lichenologist 32: 189-196; http://dx.doi.org/10.1006/lich. 1999.0254.

Matheny PB, Wang Z, Binder M, Curtis JM, Lim YW, Nilsson RH, Hughes KW, Hofstetter V, Ammirati JF, Schoch CL, Langer E, Langer G, McLaughlin DJ, Wilson AW, Frøslev T, Ge ZW, Kerrigan RW, Slot JC, Yang ZL, Baroni TJ, Fischer M, Hosaka K, Matsuura K, Seidi MT, Vauras J, Hibbett DS, 2007. Contributions of rpb2 and tef1 to the phylogeny of mushrooms and allies (Basidiomycota, Fungi). Molecular Phylogenetics and Evolution 43: 430-451; http://dx.doi.org/10.1016/ j.ympev.2006.08.024.

Miller MA, Pfeiffer W, Schwartz T, 2010. Creating the CIPRES Science Gateway for inference of large phylogenetic trees. In: Gateway computing environments workshop (GCE) New Orleans, USA, Nov 14. IEEE, pp 1-8; http://dx.doi.org/10.1109/ GCE.2010.5676129.

Rodríguez F, Oliver JF, Martín A, Medina JR, 1990. The general stochastic model of nucleotide substitution. Journal of Theoretical Biology 142: 485-501; http://dx.doi.org/10.1016/ S0022-5193(05)80104-3.

Ronquist F, Teslenko M, van der Mark P, Ayres DL, Darling A, Höhna S, Larget B, Liu L, Suchard MA, Huelsenbeck JP, 2012.
MrBayes 3.2: efficient Bayesian phylogenetic inference and model choice across a large model space. Systematic Biology 61: 539-542; http://dx.doi.org/10.1093/sysbio/sys029.

Schoch C, Seifert KA, Huhndorf S, Robert V, Spouge J, André Levesque C, Chen WFungal Barcoding Consortium, 2012. Nuclear ribosomal internal transcribed spacer (ITS) region as a universal barcode marker for fungi. Proceedings of the National Academy of Sciences of the United States of America 109: 5907-6354; http://dx.doi.org/10.1073/pnas.1117018109.

Slippers B, Coutinho TA, Wingfield BD, Wingfield MJ, 2003. A review of the genus Amylostereum and its association with woodwasps. South African Journal of Science 99: 70-74. http:// www.fabinet.up.ac.za/publication/pdfs/611-2003_slippers_ coutinho_wingfield_wingfield_sa_j_sci.pdf.

Stamanakis A, 2014. RAxML Version 8: a tool for phylogenetic analysis and post-analysis of large phylogenies. Bioinformatics 30: 1312-1313; http://dx.doi.org/10.1093/bioinformatics/ btu033.

Swofford DL, 2003. PAUP*: phylogenetic analysis using parsimony and other methods. Version 4.0b10. Sinauer, Sunderland.

Tabata M, Abe Y, 1997. Amylostereum laevigatum associated with the Japanese horntail, Urocerus japonicus. Mycoscience 38: 421-427; http://dx.doi.org/10.1007/BF02461682.

Tabata M, Abe Y, 1999. Amylostereum laevigatum associated with a horntail, Urocerus antennatus. Mycoscience 40: 535-539; http:// dx.doi.org/10.1007/BF02461032.

Tabata M, Harrington TC, Chen W, Abe Y, 2000. Molecular phylogeny of species in the genera Amylostereum and Echinodontium. Mycoscience 41: 585-593; http://dx.doi.org/ 10.1007/BF02460925.

Telleria MT, Dueñas M, Martín MP, 2014. Sistotremastrum chilensis (Trechisporales, Basidiomycota), a new species from Chilean Patagonia. Phytotaxa 158: 93-98; http://dx.doi.org/10.11646/ phytotaxa.158.1.7.

Telleria MT, Melo I, 1995. Flora Mycologica Iberica: Vol. 1. Resupinate non-poroid Aphyllophorales, I. Acanthobasidium-Cystostereum. J. Cramer, Gebrüder Borntraeger, Stuttgart.

Telleria MT, Melo I, Dueñas M, Larsson K-H, Martín MP, 2013. Molecular analyses confirm Brevicellicium in trechisporales. IMA Fungus 4: 21-28; http://dx.doi.org/10.5598/ imafungus.2013.04.01.03.

Telleria MT, Melo I, Dueñas M, Rodríguez-Armas JL, BeltránTejera E, Cardoso J, Salcedo I, 2009a. Diversity and richness of corticioid fungi (Basidiomycota) on Azores Islands: a preliminary survey. Nova Hedwigia 88: 285-308; http:// dx.doi.org/10.1127/0029-5035/2009/0088-0285.

Telleria MT, Melo I, Dueñas M, Salcedo I, Cardoso J, RodriguezArmas JL, Beltrán-Tejera E, 2008. Corticioid fungi (Basidiomycota) from the Madeira island. Mycotaxon 106: 419-422.

Telleria MT, Melo I, Dueñas M, Salcedo I, Cardoso J, RodríguezArmas JL, Beltrán-Tejera E, 2009b. Corticioid fungi (Basidiomycota) from the Azores Islands: Flores and São Miguel. Mycotaxon 109: 141-144; http://dx.doi.org/10.5248/ 109.141.

White TJ, Bruns T, Lee SJ, Taylor JW, 1990. Amplification and direct sequencing of fungal ribosomal RNA genes for phylogenetics. In: Innis MA, Gelfand DH, Sninsky JJ, White TJ (eds), PCR protocols: a guide to methods and applications. Academic Press, San Diego, pp 315-322; http://dx.doi.org/ 10.1016/b978-0-12-372180-8.50042-1. 